\title{
Cisplatin/Docetaxel/Cetuximab Regimen
}

National Cancer Institute

\section{Source}

National Cancer Institute. Cisplatin/Docetaxel/Cetuximab Regimen. NCI Thesaurus. Code C150707.

A chemoimmunotherapy regimen consisting of cisplatin, docetaxel and cetuximab that can be used for the treatment of head and neck cancer and non-small cell lung cancer (NSCLC). 